\title{
A Further Look at Conjunctive and Disjunctive Forms in Setswana
}

\author{
Anna McCormack \\ School of Oriental and African Studies, University of London
}

\begin{abstract}
Setswana distinguishes between conjunctive and disjunctive verb forms in the present positive tense. Creissels (1996) shows that this is also true of a number of other tenses (present negative, future positive and perfect positive). This work is used as a starting point to investigate the conjunctive/disjunctive distinction in my own Setswana data. Further to those presented in Creissels, there is data on the past and past progressive tenses, and environments such as relatives and subordinates. Creissels' analysis is supported by different examples, including those that do not utilise a frame intended to limit boundary effects. The are also examples not within this frame that raise questions about how flexible the conjunctive/disjunctive system can be. This paper is a work in progress.
\end{abstract}

\section{Introduction}

In this paper I will be following on from Creissels' (1996, 1998, and 1999) and others' (Chebanne et al. 1997) work on the occurrence of conjunctive and disjunctive verb forms in Setswana. I have taken these as a starting point to look again at various forms in my own Setswana data.

Setswana (Guthrie S31, part of the Sotho-Tswana group, S30) is the national and majority language of Botswana where it is spoken by approximately 1 million people. Worldwide there are approximately 4 million speakers. It is one of the 11 national languages of South Africa with approximately 3,300,000 speakers and it also spoken in Zimbabwe $(30,000$ speakers) and Namibia (6,000 speakers).

Section 2 summarises Creissels' 1996 paper, looking at some of the Setswana data that he works with and his explanation of conjunctive and disjunctive forms in different tenses. In section 3 I replicate some of Creissels' data, elicited from informants I worked with. Section 4 looks at some other examples in order to investigate some environments (that are not in Creissels' 
work) for conjunctive and disjunctive forms. In section 5 I conclude by showing how my data supports that of Creissels.

This paper is a work in progress and as such there is still much that needs to be done. Aside from not having enough examples to substantiate the conjunctive/disjunctive claims on my own data, another problem with the examples in sections 3 and 4 is that they are presented as conjunctive or disjunctive according to the intended meaning and/or the linear structure of the phrase, then taking tone into account. Better would be to look first at the conjunctive and disjunctive examples, and then at the linear structure, but this would require more space than available here. Furthermore, the data would need to be available in all of the dialects used here in order to fully account for the dialectal differences. This is a matter for future research.

\section{Summary of Creissels}

Creissels finds that there are several tenses in Setswana in which a distinction between conjunctive and disjunctive verb forms can be found and that they are realised only through tonal differences, apart from one exception (the present positive) where the distinction is also expressed by a segmental morpheme $a$. The "conjunctive" form is the equivalent to Meeussen's (1959) conjoint verb in Kirundi, or the "strong" link as found in Sharman (1956). Its use suggests that the verb is not in clause final position and anything following is "new" information. The "disjunctive" verb form is equivalent to Meeussen's disjoint verb, or Sharman's "weak" link. The disjunctive verb form occurs when the verb is in clause final position and anything that may follow it is a 'postclausal topic' (Creissels 1996, 109).

All of the examples in this section (section 2) are from Creissels $1996 .{ }^{1}$

1 At this stage it is important to make a mention of the issue of orthography. The standard orthography of Setswana is not a disjunctive system, making clause boundaries difficult to identify. Tonal variations do not only effect individual elements or words but necessitate looking at an entire verb form or clause. Creissels represents the verb forms as one word (for example: difula, diafula - see examples (1) and (2) for contrast with this). I have chosen to illustrate the verb forms and clauses in question through the use of bold type. In the relevant paper (1996), Creissels presents his examples without a morphological gloss, but with a full phonetic transcription. I have chosen not to follow in his example and have omitted the phonetic transcription from my presentation of Creissels' data, but have provided a morphological gloss. These glosses are my own, even for those of Creissels' data and any mistakes in the glossing are my own also. Furthermore, only the surface tones have been marked in this paper. This is due to time and space constraints limiting discussion of phonological processes. 


\subsection{Present positive}

I will begin with the present positive tense because the conjunctive/disjunctive distinction can be seen easily - without having to look at tone markings - as the disjunctive is marked by $a$.

In this tense the distinction between conjunctive and disjunctive can be seen through the use of the disjunctive marker $a$ between the subject marker (SM) and the verb, as can be seen in example (2). ${ }^{2}$ It is important to note that the disjunctive marker is found only in disjunctive examples. However, disjunctive examples are not only marked through the use of the disjunctive marker, but also through distinct tonal patterns - we will come to these examples later on.

Short form - conjunctive: ${ }^{3}$
(1)
dî-kgòmó dî̀
dî fúlà
fúlà kwá nòké-ǹg
CL10-cow SM10 graze LOC river-LOC

'The cows graze/are grazing at the river' Creissels 1996, 109, ex. (2)

Long form - disjunctive:

(2) dî-kgòmó dî $\quad$ á fúlà
CL10-cow
'The cows
'Traze/are grazing'

Creissels 1996, 109, ex. (1)

In these first two examples we can see that the short form of the verb does not occur in sentence final position whereas the long form does. In terms of the conjunctive/disjunctive distinction, in sentence final or prepausal position only the disjunctive form can be used, whereas both the conjunctive and disjunctive forms can be used in the non-prepausal position (though the conjunctive form is found here more often).

2 Creissels calls this a 'formative [a]'. It should not be confused with a Subject Marker. An [a] is found in examples both as a disjunctive marker (in which case it will be glossed 'DISJ') and as a subject marker (in which case it will be glossed 'SM').

3 The glosses used in this paper are as follows:

\begin{tabular}{|c|c|c|c|c|c|}
\hline $1 \mathrm{SG}$ & $=$ & $1^{\text {st }}$ Person Singular & DISJ & $=$ & Disjunctive Marker \\
\hline $2 \mathrm{SG}$ & $=$ & $2^{\text {nd }}$ Person Singular & FUT & $=$ & Future \\
\hline $2 \mathrm{PL}$ & $=$ & $2^{\text {nd }}$ Person Plural & LOC & $=$ & Locative \\
\hline $3 \mathrm{SG}$ & $=$ & $3^{\text {rd }}$ Person Singular & NEG & $=$ & Negative \\
\hline 3PL & $=$ & $3^{\text {rd }}$ Person Plural & OM & $=$ & Object Marker \\
\hline CL & $=$ & Class & PFT & $=$ & Perfect \\
\hline CONS & $=$ & Consecutive & PST & $=$ & Past \\
\hline CONJ & $=$ & Conjunction & REL & $=$ & Relative \\
\hline COP & $=$ & Copula & $\mathrm{SM}$ & $=$ & Subject Marker \\
\hline
\end{tabular}


(1) and (2) illustrate the disjunctive and conjunctive forms in cases where the verb either is or is not followed by a complement. (4) and (5), and the others which follow in this section, are within a frame used to eliminate the effects of the prepausal position on the basic tonal melody. The frame is: the subject marker preceding the verbal base, and the conjunction and full pronoun following the verb. It is illustrated in (3):

(3) kè bînà lé èné

Subject Marker Verb-'dance' Conjunction Full Pronoun-3SG

'I dance/am dancing with him/her' Creissels 1996, 110, ex. (4) Short form - conjunctive:

(4) bá bînà lé bòné

SM3PL dance CONJ 3PL

'They dance/are dancing with them' Creissels 1996, 110, ex. (6) Long form - disjunctive:

$\begin{array}{lllll}\text { (5) bá } & \text { à } & \text { bîná } & \text { lé } & \text { bòné } \\ \text { SM3PL } & \text { DISJ } & \text { dance } & \text { CONJ } & 3 \mathrm{PL}\end{array}$

'They too dance/are dancing' Creissels 1996, 110, ex. (5)

With (4) and (5) we can see that it is purely the context of the sentence (what it actually means) that determines whether the short or long, or conjunctive or disjunctive, form is used. Furthermore, due to the conjunction le introducing a pronoun that can either refer to the subject or not, the actual intended meaning can only be seen through the use of the conjunctive or disjunctive form: when the pronoun introduced by lé does not refer to the subject, the verb is in the conjunctive but when the pronoun introduced by le does refer to the subject, the verb is in the disjunctive.

Creissels argues that, syntactic differences aside, the tonal differences in these last two examples must reflect the conjunctive/disjunctive distinction (rather than the postverbal boundary) because otherwise the long form would have the same tonal melody in all contexts (which would be with a low (L) final tone, the same as if immediately followed by a pause), whether followed by a pause or not, and that the melody found in the long (disjunctive) form (with two final high $(\mathrm{H})$ tones) should actually represent the short (conjunctive) form.

\subsection{Present negative}

The present negative tense supports the arguments raised in section 2.1 (that context determines whether the verb form is conjunctive or disjunctive and that differences in the tonal melody reflect the conjunctive/disjunctive distinction), the only difference being that the distinction between the conjunctive and 
disjunctive forms can only be seen through the tonal differences. These examples do not have a disjunctive marker.

Conjunctive:

$\begin{array}{lllll}\text { (6) gà } & \text { bá } & \text { bîné } & \text { lé } & \text { bòné } \\ \text { NEG } & \text { SM3PL } & \text { dance } & \text { CONJ } & 3 P L\end{array}$

'They do not dance/are not dancing with them'

Creissels 1996, 110, ex. (14)

Disjunctive:

(7) gà bá bînè lé bòné

NEG SM3PL dance CONJ 3PL

'They do not dance/are not dancing either' Creissels 1996, 110, ex. (13)

Conjunctive:

(8) gà ké bîné lé èné

NEG SM1SG dance CONJ 3SG

'I do not dance/am not dancing with him/her'

Creissels, 1996, 110, ex. (12)

Disjunctive:

(9) gà ké bînè lé ǹná

NEG SM1SG dance CONJ $1 \mathrm{SG}$

'I do not dance/am not dancing either' Creissels, 1996, 110, ex. (11)

(6) and (8) are in the conjunctive form. The verb forms have a final $\mathrm{H}$ tone. Compare these with (7) and (9), which are in the disjunctive form and have a final L tone. All other tones within these examples are the same, it is the final tone of the verb form that distinguishes between conjunctive and disjunctive.

\subsection{Future positive}

The tonal differences between pairs of examples across tenses are not always the same. This supports the earlier case for tonal differences being related to the conjunctive/disjunctive distinction.

Compare the pairs of examples in the present negative tense (section 2.2) with the ones below. In the present negative the conjunctive/disjunctive pairs show the same tonal variation in the different forms: conjunctive has two final high tones $(\ldots \mathrm{HH})$ on the verb, disjunctive has final high-low tones (...HL). In the future positive tense the example pairs show that the conjunctive form has ...HL tones and the disjunctive form has ...HH tones - the reverse of what is found in the present negative. 
Conjunctive:
(10) kè
tlàà bînà lé èné
SM1SG shall dance CONJ 3SG
'I shall dance with him/her'

Creissels 1996, 110, ex. (8)

Disjunctive:
(11) kè
tlàà bîná lé ǹná
SM1SG shall dance CONJ 1 SG
'I too shall dance'

Conjunctive:

$\begin{array}{lllll}\text { (12) bá } & \text { tláà bînà lé } & \text { bòné } \\ \text { SM3PL } & \text { shall dance } & \text { CONJ } & 3 \mathrm{PL}\end{array}$

'They will dance with them'

Creissels 1996, 110 , ex (7)

Disjunctive:
(13) bá
tláà bîná lé
bòné
SM3PL shall dance CONJ 3PL
'They too will dance'

Creissels 1996, 110, ex. (9)

(10) and (12) are in the conjunctive as is illustrated by the verb forms having final ...HL tones, as compared with (11) and (13) which are both in the disjunctive and have final ...HH tones on the verb forms.

Within the example pairs in this section both have the same tones, apart from verb finally. Between the pairs, however, looking at the relevant verb form (in bold), we can see that the pairs have very different tone markings. The $\mathrm{H}$ tones on the second syllable in (12) and (13) are due to $\mathrm{H}$ tone spread from the (H toned) SM bá on to an underlyingly L-toned syllable immediately following the SM. We can tell that there is $\mathrm{H}$ tone spread rather than the second syllable having an underlying $\mathrm{H}$ tone, by comparing (12) and (13) (which both have a $\mathrm{H}$ tone SM) with (10) and (11). Both (10) and (11) have a L-toned SM. H tones in Setswana are "active" and L tones are "inert" (Creissels 1998, 136), this means that an underlying $\mathrm{L}$ tone will become $\mathrm{H}$ if there is any $\mathrm{H}$ tone that can extend its domain to cover that $\mathrm{L}$ tone. Because of the $\mathrm{L}$ tones following the SM in (10) and (11) we know that the $\mathrm{H}$ tone following the SM in (12) and (13) are due to $\mathrm{H}$ tone spread. This is the reason for the tonal variation between these example pairs. ${ }^{4}$ 4 There is not enough space here to discuss H tone spread, but Creissels (1998) has a full
discussion and description of this. 


\subsection{Perfect positive}

So far in the examples we have looked at, where the conjunctive/disjunctive distinction can be seen tonally, the distinctive tone can be found on the final syllable of the verb, meaning that the different examples still look similar.

In the perfect positive tense the distinction is found on syllables towards the end of the verb stem and on the syllable immediately following the SM. Therefore the conjunctive and disjunctive forms have very different tonal realisations.

Conjunctive:

(14) bá jélè lé bòné

SM3PL eat.PFT CONJ 3PL

'They have eaten with them' Creissels 1996, 111, ex. (22)

Disjunctive:

$\begin{array}{llll}\text { (15) bá jèlé lé bòné } & \\ \text { SM3PL } & \text { eat.PFT } & \text { CONJ } & \text { 3PL }\end{array}$

'They too have eaten'

Creissels 1996, 111, ex. (21)

(14) is in the conjunctive and has HL tones on the (short) verb form. Compared with (15), the tonal realisations are very different. (15) is in the disjunctive and has LH tones on the verb form.

Contrary to the examples found in the future positive tense, the tonal differences on the verb form are not to do with $\mathrm{H}$ tone spread. We can see this by looking at the tone immediately following the SM in (15). If $\mathrm{H}$ tone spread were involved in these examples we would not find a $\mathrm{L}$ tone in the second syllable of (15), due to the reasons given at the end of section 2.3 above.

Conjunctive:

(16) bá tsàmáílè lé bòné

SM3PL go.PFT CONJ 3PL

'They have gone with them'

Creissels 1996, 111, ex. (26)

Disjunctive:

(17) bá tsámàilè lé bòné

SM3PL go.PFT CONJ 3PL

'They too have gone'

Creissels 1996, 111, ex. (25)

Unlike in other tenses, the verb final syllables of (16) and (17) are the same in both examples, but we can see that it is the syllables immediately following the SMs and the penultimate and antepenultimate syllables of the verb forms which carry the conjunctive/disjunctive distinction in this tense. (16) is conjunctive 
and has LHHL tones on the verb form while (17) has HLLL tones on the verb form (with the final $\mathrm{L}$ tones not being distinctive).

\section{Further Data}

I elicited Creissels' data from my own Setswana speaking informants. I elicited language samples that were as spontaneous as possible to see what would happen without using Creissels' frame (example (3) in section 2.1). Therefore I did not ask informants what they understood by the sentences presented in section 2, but rather elicited data as close in the conjunctive/disjunctive interpretation as possible to that presented in section 2. The examples here are from a Sekgatla dialect speaker. The informant from which Creissels' data was elicited spoke a different dialect, Sengwaketse. I mention this to account for any lexical differences between Creissels' data and my own.

\subsection{Present positive}

In this tense it is a disjunctive marker that distinguishes between the conjunctive and the disjunctive (section 2.1).

Short form - conjunctive:
(18) dî-kgòmó dî
dî fúlà kó nòké-ǹg
CL10-cow SM10 graze LOC river-LOC
'The cows graze at the river'

Sekgatla

Long form - disjunctive:
(19) dî-kgòmó dî á fúlà
CL10-cow SM10 DISJ graze

'The cows graze'

Sekgatla

The conjunctive form is not phrase final and has no disjunctive marker, while the disjunctive form $i s$ phrase final and has a disjunctive marker.

Conjunctive:
(20) kè bînà lé èné
SM1SG dance CONJ $3 \mathrm{SG}$
'I am dancing with him'

Sekgatla

Disjunctive:
(21) lé ǹná ké à bînà
CONJ 1SG SM1SG DISJ dance
'I too dance'

Sekgatla 
In (20) we find the exact same tone markings for the present positive conjunctive as found by Creissels (example (3)). (21), however, is not as expected. It is a disjunctive example, primarily because it has the disjunctive marker. It is also in phrase final position, which, though different from Creissels (see example (5)), is perfectly acceptable (see example (2)). However, the tones are not what is expected. Firstly, the SM has a $\mathrm{H}$ tone where it is ordinarily Ltoned. I believe this to be due to $\mathrm{H}$ tone spread from the preceding pronoun. Secondly, the verb has a final L tone where we would expect a final $\mathrm{H}$ tone in the disjunctive. I do not believe this to be a great problem, however, because the disjunctive marker and the clause being in phrase final position are enough for the example to be disjunctive (in this tense) and the final $\mathrm{L}$ tone may be to do with the fact that the verb is in clause final position and is subject to the tonal effects brought about by that (and which Creissels was avoiding through his use of a frame for the verb form).

What is also interesting, and illustrated by (21), is that my informants preferentially fronted the conjunction lé + pronoun in disjunctive examples.

\subsubsection{Postverbal NPs}

The following postverbal NP examples are all in the present positive tense and so should show the conjunctive/disjunctive distinction through a disjunctive marker, as well as tonally.

Conjunctive:

(22) kè rátá Mphó

SM1SG like Mpho

'I like Mpho'

Sengwato

Disjunctive:
(23) kè
à mó-rátà
SM1SG DISJ OM1-like
'I like him'

Sengwato

(22) is conjunctive. The verb is not phrase final and there is no disjunctive marker. However, the tones are not the same as those that have been found by Creissels (whose conjunctive example has a final L tone, see example (4)). (23) is disjunctive. The verb form is phrase final and there is a disjunctive marker. However, the tones are not the same as those found by Creissels (whose disjunctive example has a final $\mathrm{H}$ tone, see example (5)), but this verb is in phrase final position (unlike in example (5)) and so subject to the tonal effects that come from that.

(In the following example 'I.B.' stands for Intonation Break.) 
Disjunctive:
(24) kè à mó-rátà
SM1SG DISJ OM1-like
(I.B.) Mphó
Mpho
'I like him Mpho'

Sengwato

(24) is disjunctive. The verb is phrase final and there is a disjunctive marker. In spite of the verb being followed by a noun, the reading is still disjunctive due to the intonation break between the verb form and the noun, making Mpho an afterthought topic and thus not changing the disjunctive reading.

\subsection{Present negative}

In this tense the conjunctive/disjunctive distinction can only be seen through tonal variation, conjunctive forms have a final $\mathrm{H}$ tone while disjunctive forms have a final $\mathrm{L}$ tone (section 2.2).

Conjunctive:

(25) gà bá bîné lé bòné

NEG SM3PL dance CONJ 3PL

'They are not dancing with them'

Disjunctive:

$\begin{array}{lllll}\text { (26) gà } & \text { bá } & \text { bînè lé } & \text { bòné } \\ \text { NEG } & \text { SM3PL } & \text { dance } & \text { CONJ } & \text { 3PL }\end{array}$

'They too are not dancing'

Sekgatla

(26) corresponds to the sentence elicited by Creissels. It is interesting in terms of my data, however, because the relevant verb form is not phrase final, which I have found to be the predominant structure of disjunctive examples.

Conjunctive:

(27) gà ké bîné lé èné

NEG SM1SG dance CONJ 3SG

'I am not dancing with him'

Sekgatla

Disjunctive:

(28) lé ǹná gà ké binè

CONJ 1SG NEG SM1SG dance

'I too do not dance'

Sekgatla

(25) and (27) correspond with what Creissels found in example (6). The conjunctive verb form is not phrase final and has a final $\mathrm{H}$ tone. (28) also 
corresponds, tonally, with what Creissels found, although the relevant clause is phrase final whereas in his corresponding example (see (7)) it is not phrase final. I do not see this as being a problem as the disjunctive form is comfortably used phrase finally (unlike the conjunctive form). The only issue raised with this example is whether the verb final (and also phrase final) L tone is due to the example being disjunctive or due to the verb being phrase final and the resulting tonal effects.

\subsection{Future positive}

In this tense conjunctive verb forms have a final ...HL tonal melody on the verb, while the disjunctive forms have a ...HH tonal melody (section 2.3).

Conjunctive:
(29) kè
tlà bînà lé èné
SM1SG FUT dance CONJ 3SG
'I shall dance with him'

Sekgatla

Disjunctive (?):
(30) lé ǹná ké tlà bînà
CONJ 1SG SM1SG FUT dance
'I too shall dance'

Sekgatla

(29) corresponds to what Creissels found (example (10)), the relevant verb form is not phrase final and has a ...HL tonal melody on the verb.

Structurally (30) is fine, especially with my informants, because it is in the disjunctive position, but the tones are not what is expected here. Disjunctive forms in the future positive tense should have a ...HH tonal melody, but here we find a ...HL - the same as in the conjunctive form. This could be because the verb is in phrase final position in addition to being clause final. The SM is $\mathrm{H}$ toned where a $\mathrm{L}$ tone is expected, possibly due to $\mathrm{H}$ tone spread from the preceding pronoun as in example (21).

Conjunctive:
(31) bá
tlà bînà lé
bòné
SM3SG FUT dance CONJ 3PL
'They will dance with them'

Sekgatla

Disjunctive (?):
(32) lé
bòné bá
tlà bînà
CONJ 3PL SM3SG FUT dance
'They too shall dance'

Sekgatla 
(31) corresponds with what Creissels found (see example (12)). The conjunctive verb form is not phrase final and has a final ...HL tonal melody.

Both (30) and (32) have a disjunctive interpretation though the tones do not reflect this. If we are looking purely tonally then this is not a disjunctive form, but if we allow for the distinction to be seen structurally in other tenses as it is in the present positive, and also take into account the possibility of phrase boundary tonal effects, I pose the question of whether these examples could still be in the disjunctive?

\subsection{Perfect positive}

In this tense Creissels says the tonal difference is found on the syllable immediately following the SM and on the syllables towards the end of the verb stem (section 2.4). While my examples are like Creissels' in terms of tone on the verb form, they differ with respect to the tone of the SM. In these examples the SM itself has a different tone depending on whether it is conjunctive or disjunctive.

Conjunctive:

$\begin{array}{llll}\text { (33) bà } & \text { jélè } & \text { lé } & \text { bòné } \\ \text { SM3PL } & \text { eat.PFT } & \text { CONJ } & \text { 3PL }\end{array}$

'They have eaten with them'

Disjunctive:

(34) bá jèlé lé bòné

SM3PL eat.PFT CONJ 3PL

'They too have eaten'

Sekgatla

bá jèlé lé bòné
SM3PL eat.PFT CONJ $3 \mathrm{PL}$
'They too have eaten'

(34) corresponds to the disjunctive form found by Creissels. It also has the expected $\mathrm{H}$ tone on the SM.

In the following examples the SMs, again, have different tones in the conjunctive and disjunctive. My Sekgatla speaking informant was consistent in the SM tones. In both conjunctive examples in this tense the SM has a $\mathrm{L}$ tone and in both disjunctive examples the SM has a $\mathrm{H}$ tone. Example (35), apart from the wayward SM, corresponds to the conjunctive as found by Creissels. The syllable immediately following the SM is L toned and the penultimate and antepenultimate syllables are both $\mathrm{H}$ toned.

Conjunctive:
bà tsàmáîlè lé bòné
SM3PL go.PFT CONJ 3PL
'They have gone with them'

Sekgatla 
Disjunctive (?):

(36) bá tsámáîlè lé bòné
SM3PL go.PFT CONJ 3PL
'They too have gone'

Sekgatla

The only tonal variation in (36) is on the syllable immediately following the SM (compare with example (17)). The sentence elicited should have a disjunctive reading as is clear from the syntactic context and the interpretation. The tone immediately following the SM is fine and is as expected (see example (17)) but the rest of the verb is the same as the conjunctive form in (16) and (35). The final L tone cannot result from phrase finality effects because it is not phrase final, it could be due to dialectal differences.

I do not believe that the L toned SM is a dialectal difference because (34) and (36) have a $\mathrm{H}$ toned SM, with (33) and (35) in the conjunctive also having a $\mathrm{L}$ toned SM. These data suggest the SM may be part of the conjunctive marking in the perfect positive tense, which differs from the data described by Creissels (section 2.4, examples (14) - (17)) where the conjunctive/disjunctive marking occurs only on the verbal base and does not extend to the SM.

\subsubsection{Presentational/locative}

The examples in this section are all postverbal NPs but are to do with presentational or locative in the perfect positive tense.

Conjunctive:

(37) gó $\quad$ tsîlé $\quad$ Mphó

'There came Mpho'

Sekgatla

Disjunctive:

(38) Mphó ó tsîlè

Mpho SM2SG come.PFT

'Mpho came'

Sekgatla

(37) appears to be in the conjunctive because the verb is not phrase final. In (38) the verb is in phrase final position and has a markedly different tone melody from (37), this would suggest a tonally marked conjunctive/disjunctive

5 [gó] fulfils different functions in Setswana. For example it is the class 15 infinitival marker as in 'to write a letter...' - go kwala lekwalo. Here it is used as a locative subject marker. 
distinction. However, there is a problem with the perfect positive in that the tones are subject to phonological rules within Setswana, making any predictions about tonal distinctions difficult without further research. There is further, though brief, discussion of this tense in section 4.2.

Disjunctive:

$\begin{array}{lll}\text { ó } & \text { tsîlè } & \text { Mphó } \\ \text { SM2SG } & \text { come.PFT } & \text { Mpho } \\ \text { 'He came, Mpho' } & \end{array}$

(39) would appear to be a contradiction to what has already been said in this section because I have ascribed a disjunctive interpretation even though the verb form is immediately followed by the noun, making it, structurally, conjunctive. However, the translation has a comma between the verb form and the noun and my informant was very insistent that it was there. Therefore Mpho is analysed as an after-thought topic (even though there is no clearly realised intonation break) and the example is disjunctive, showing the conjunctive/disjunctive distinction is sensitive to syntactic context.

This section has shown it is largely the case that the replicated data matches the original data from Creissels. The differences that are evident could be attributed to the replicated data not making use of Creissels' frame and thus being open to phonological boundary effects, or could be due to dialectal differences between speakers. There would need to be more extensive work done on this matter.

\section{Other Environments}

The following are environments not in the data presented by Creissels in the referenced works. I look briefly at them here to see if there is a conjunctive/disjunctive distinction and whether it fits in with Creissels' generalisations regarding which tonal melodies are expected within tenses to show a conjunctive/disjunctive distinction. The data in this section are from speakers of the Sekgatla and Sengwato dialects of Setswana. I mention this in order to account for any lexical differences between Creissels' data and my own, and also within my data.

In the following data it is difficult to asses the phonological evidence for a conjunctive/disjunctive distinction because a full tonal paradigm and systematic analysis using the tonal processes operating in Setswana would be required and there is neither time nor space to include such in this paper. Looking at the data presented so far, and that from Creissels, there is a syntactic correlation between the conjunctive and the disjunctive which can be formulated as saying that a 
conjunctive is followed by a complement, or at least is never phrase final, while the disjunctive predominantly occurs phrase finally but not always. ${ }^{6}$ Taking this into account I have assigned labels to examples (either conjunctive or disjunctive) within this section based on the syntactic interpretation of the sentence and then looked at the tonal melody.

\subsection{Relatives}

Setswana has a specific relative marker that occurs on the verb form: $-n^{\prime} g,{ }^{7}$ which always carries a $\mathrm{H}$ tone. This $\mathrm{H}$ tone means that relative forms "have no tonal alternation" (Chebanne et al. 1997:199), excepting phonological rules that are to do with H tone domains. Furthermore, Chebanne et al. (1997: 199) say that there is no conjunctive/disjunctive distinction with the relative, and this is what I hope to discover with my own data.

The following examples are in the past (as can be seen from the past tense marker) and there is no mention of the past tense with the relative clause in the referenced works. I was hoping to see what would happen in the past and there does seem to be a difference with the relative.

Conjunctive (?):

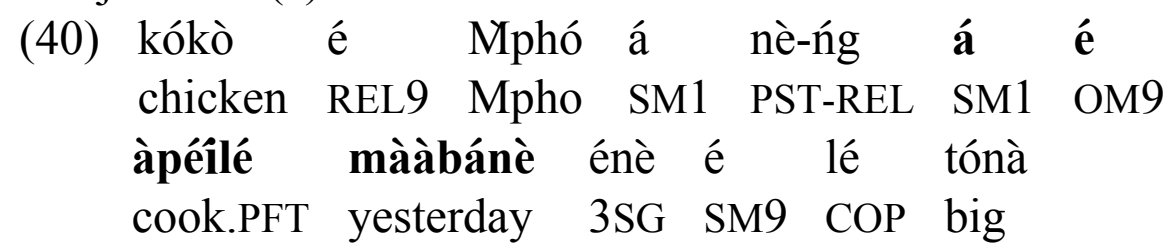

'The chicken which Mpho cooked yesterday was big'

Sekgatla

In (40), the relative clause could be conjunctive because the verb is not final within the clause (being followed by maabane, 'yesterday') and the verb form has a final $\mathrm{H}$ tone, which contrasts with (41).

Disjunctive (?):

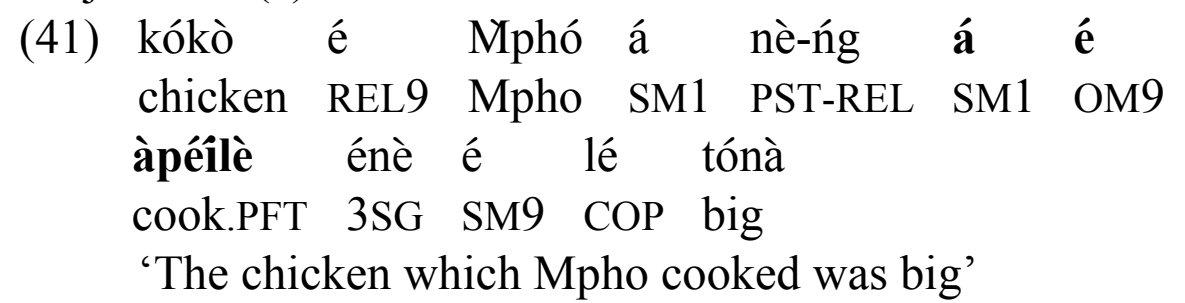

6 For the present purposes there is no full syntactic analysis of this as it is a matter for further investigation.

7 This marker is not to be confused with the locative marker found earlier on. The difference between the two is found tonally. The locative marker has a low tone -ǹg while the relative marker has a high tone -ńg. 
In (41), the relative clause could be disjunctive because, within the clause, nothing follows the verb and the verb form has a final low tone (which contrasts with (40)). However, there is no disjunctive marker between the SM and the verb form. In this instance the tonal differences are most likely due to postverbal boundary effects, rather than a conjunctive/disjunctive distinction.

\subsection{Subordination}

This section looks at the effects of subordinate clauses on the preceding verb form in two contexts. Firstly, when the subordinate clause is fronted in two different tenses and, secondly, when the verb form is not immediately followed by the subordinate clause.

The two following examples are in the future positive. In (42) the subordinate clause follows the main clause, but in (43) it is fronted.

Conjunctive:

ó tá mò-phîthélà fá ó-tà

SM2SG FUT OM1SG-find if SM2SG-come

'You will find me if you come'

Sengwato

Disjunctive (?):
(43) fá ó-tá
ò tà
m̀̀-phîthèlà
if SM2SG-come
SM2SG FUT
OM1SG-find
'If you come you will find me'

Sengwato

According to Creissels, the conjunctive form in the future positive tense has a verb final tonal melody ...HL, see section 2.3. That is what we find in (42). Structurally (43) is disjunctive but this is not supported by the tonal melody. The disjunctive form in the future positive tense should have a verb final tonal melody ...HH. The final $\mathrm{L}$ tone could be $\mathrm{L}$ instead of $\mathrm{H}$ because the verb is phrase final and subject to the effects of that position, but the penultimate syllable of the verb form is also $\mathrm{L}$ which is different from what is predicted.

In the following two examples, the clause that we are looking at is in the perfect positive (the $b \grave{o}$ in both changes the interpretation of the entire sentence, but we are looking at a specific clause which is in the perfect positive): ${ }^{8}$

8 I am not sure how to gloss the bò in the following example (44). It provides the meaning of 'would' to the sentence and so that is how I have glossed it. 
Conjunctive (?):

$\begin{array}{lllll}\text { (44) ò } & \text { ká } & \text { bò } & \text { ó } & \text { ḿ-phîthétsé } \\ \text { SM2SG } & \text { TNS } & \text { would } & \text { SM2SG } & \text { OM1SG-find.PFT } \\ \text { fá } & \text { ó } & \text { né } & \text { ó-tsilé } & \\ \text { if } & \text { SM2SG } & \text { PST } & \text { SM-come.PFT } & \\ \text { 'You would have found me if you had come' }\end{array}$
Disjunctive (?):

$\begin{array}{lllll}\text { (45) fá } & \text { ó } & \text { né } & \text { ó-tsilé } & \\ \text { if } & \text { SM2SG } & \text { PST } & \text { SM2SG-come.PFT } & \\ \text { ò } & \text { ká } & \text { bò } & \text { ó } & \text { mí-phîthétsè } \\ \text { SM2SG } & \text { TNS } & \text { would } & \text { SM2SG } & \text { OM1SG-find.PFT }\end{array}$

'If you had come you would have found me' Sengwato

(44) is structurally conjunctive. (45) is structurally disjunctive. It is difficult with this tense to know what tonal melodies show a conjunctive/disjunctive distinction. The examples cited by Creissels (see examples (14)-(17)) all have different tonal melodies. There does not seem to be an obvious pattern as to which tones correspond to a conjunctive form and which to a disjunctive form and so I believe that the tones are subject to the phonological rules that already exist in Setswana. ${ }^{9}$ These examples require more research and investigation.

The following examples are in the past progressive. There is no mention of the past progressive tense interacting with subordinates in the referenced works and so the interpretation of the examples below is still sketchy.

Conjunctive:

(46) kè nè ké àpéilè kókó fá á górògà SM1SG PST SM1SG cook.PFT chicken when SM1 arrive 'I was cooking chicken when he arrived' Sengwato

(46) is conjunctive because the verb form is not clause final within the relevant clause. The present positive tense (as well as having a disjunctive marker) and the present negative tense both show the conjunctive/disjunctive distinction on the final syllable of the verb form (see examples (4) and (5) for the present positive), so it can be suggested that the verb form in (46) is in the conjunctive because it has a final L tone, which differs to that found in (47) which is in the disjunctive and has a final $\mathrm{H}$ tone.

9 Which I do not have the space to discuss in this paper, but see Creissels (1998) and (1999). 
Disjunctive:

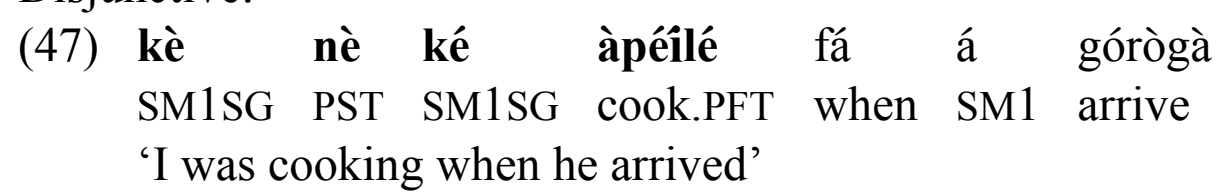

Sengwato

(47) is in the disjunctive because the verb form is clause final within the relevant clause. Furthermore, compared with (46), there is a tonal distinction on the final syllable of the verb form.

There are two issues that come out of this section. Firstly there is the question of whether there actually is a conjunctive/disjunctive distinction with subordinates, and secondly, whether subordinate clauses count as being relevant postverbal material and so have an effect on the conjunctive/disjunctive distinction in the first place. Within this last point there are further questions that arise as to the nature of the different subordinate clauses and whether this may make a difference. At the beginning of this section (examples (42)-(45)) we find the subordinate clause is an 'if' clause. The differing tonal melodies could indicate that 'if' clauses do count as following the verb, especially if we compare with (46) and (47) which have 'when' clauses in the subordinate clause. These data seem to show that 'when' clauses do not count as postverbal material in the relevant sense. These are matters that require more data and investigation in order to come to a conclusion.

\section{Conclusion}

The data found in section 3, on the whole, shows the same results as presented in Creissels' referenced works - though it does raise questions about the possible conclusions to be drawn from examples that do not fit his model, especially without the use of the frame that he utilises to ensure there is no boundary effects on the tonal melody (for instance, examples (45) and (47)). One such question we could ask at this stage is whether the generalization presented by Creissels can be extended to 'almost examples', such as those in (41) and (44)?

In terms of the 'other environments' (section 4), these require a lot more investigation and analysis. At this stage it is difficult to say what is happening with these examples because they are so few and not enough to build a full picture. Particularly interesting is what is happening with relatives and subordinates but these require a lot more time and study.

To sum up: My data fully supports Creissels' observation. It does seem to me that there is a lot more going on tonally in Setswana than simply the effects of phonological boundaries. However, the different, and sometimes conflicting, data raises more questions than it answers and opens doors for future research. 


\section{References}

Chebanne, A. M., Creissels, D. \& H.W. Nkhwa (1997) Tonal Morphology of the Setswana Verb. München, Newcastle: Lincom Europa.

Creissels, D. (1996) Conjunctive and disjunctive verb forms in Setswana. South African Journal of African Languages 16 (4): 109-115.

Creissels, D. (1998) Expansion and retraction of high tone domains in Setswana. In: Larry M. Hyman \& Charles W. Kisseberth (eds.) Theoretical Aspects of Bantu Tone. Stanford, California: CSLI, 133-194.

Creissels, D. (1999) The role of tone in the conjugation of Setswana. In Blanchon, Jean A. \& Denis Creissels (eds); Issues in Bantu Tonology. Köln: Rüdiger Köppe Verlag, 109152.

Meeussen, A.E. (1959) Essai de Grammaire Rundi. Tervuren: Annales du Musee Royal du Congo Belge, Serie Sciences Humaines, 24.

Rose, S., Beaudoin-Leitz, C. \& D. Nurse (2002) A Glossary of Terms for Bantu Verbal Categories, With Special Emphasis on Tense and Aspect. München: LINCOM Europa.

Sharman, J.C. (1956) The tabulation of tenses in a Bantu Language (Bemba: Northern Rhodesia). Africa 26: 29-46.

twoblueoranges@yahoo.co.uk 